\title{
Resilient Organizations for River Restoration: The Case of Two Colorado River Sub-Basin Recovery Programs
}

\author{
Jaishri Srinivasan*, Theresa E. Lorenzo, Michael L. Schoon and Dave D. White \\ School of Sustainability, Arizona State University, Tempe, AZ, United States
}

This study characterizes the resilience of organizations undertaking river basin governance and recovery. The Upper Colorado River Endangered Fish Recovery Program (UCREFRP) and the Lower Colorado River Multi-Species Conservation Program (LCR-MSCP) are defined in this study as polycentric organizations nested within larger institutional mechanisms governing the Colorado River Basin. This study utilizes an environmental disturbance-organizational response framework to characterize organizational resilience-and uses attitudinal diversity (characterized by attitudes toward

OPEN ACCESS

Edited by:

Leon M. Hermans, Delft University of

Technology, Netherlands

Reviewed by:

Anamika Barua,

Indian Institute of Technology

Guwahati, India

Nihit Goyal,

Delft University of

Technology, Netherlands

*Correspondence: Jaishri Srinivasan jaishris@asu.edu

Specialty section: This article was submitted to Water and Human Systems,

a section of the journal

Frontiers in Water

Received: 29 June 2021 Accepted: 01 November 2021 Published: 06 December 2021

Citation:

Srinivasan J, Lorenzo TE, Schoon ML and White DD (2021) Resilient Organizations for River Restoration: The Case of Two Colorado River Sub-Basin Recovery Programs.

Front. Water 3:733117. doi: 10.3389/frwa.2021.733117 agendas) as the measurable metric. Environmental disturbances are defined as either press or pulse and categorized as either institutional or biophysical in nature. Four types of attitudinal diversity metrics are utilized-supportive, clarifying, conditional, and critical. Results indicate that institutional press and pulse events generated anticipatory resilience capabilities along with some adaptive capabilities for the organizations. However, the biophysical press and pulse events only reveal coping capabilities and very little adaptive capabilities. With the recent Colorado River shortage declaration, it is critical for the programs to build anticipatory as well as adaptive capabilities for optimal response to biophysical press events.

Keywords: resilience (environmental), adaptive planning and management, attitude-behavior relationships, river basin agencies, organizational resilience, river restoration and conservation

\section{INTRODUCTION}

Governance at the river basin scale started formally with the application of the Integrated Water Resources Management (IWRM) approach, the first notable example of which is the Tennessee Valley Authority (TVA) in 1933 (GWP, 2002). This was followed by the establishment of the United States Bureau of Reclamation that was instrumental in facilitating the subsidized expansion of irrigated agriculture in the Western part of the US as well as construction of large public works (Snellen and Schrevel, 2004). The resulting pathology of water resource management was a reduction in the natural variation in a system creating a loss of resilience (Holling and Meffe, 1996). The Global Water Partnership (GWP) definition of IWRM included integration across development and management for economic and social welfare in an equitable manner without compromising the sustainability of vital ecosystems (GWP-TEC, 2000; Medema and Jeffrey, 2005).

Criticisms about IWRM rest on contentions that it remains a normative theory with very little empirical evidence of purported benefits (Jeffrey and Gearey, 2004). Furthermore, there is no agreement on fundamental issues like what aspects should be integrated, how, by whom, or even if such integration in a wider sense is possible (Biswas, 2004). Adaptive management 
has been put forward as an enhancement to the prevailing IWRM. Adaptive management has its roots in ecosystem management and refers to a systemic process of continually improving management policies and practices through learning, with the outcome of increasing the adaptive capacity of the system with proposed institutional design requirements outlined (Pahl-Wostl and Sendzimir, 2005). Furthermore, significant literature and theories have been developed toward adaptive governance (Huntjens et al., 2011, 2012), complexity governance (Pahl-Wostl et al., 2010), and social learning in water systems (Pahl-Wostl, 2009; Johannessen et al., 2019).

Long-term institutional analysis, especially of those for managing natural resource use or allocations have been subject to extensive study resulting in multiple diagnostic frameworks (Ostrom, 1990, 2009, 2011; Anderies et al., 2004). The dominant paradigm of environment as a consumer falls short when the environment itself (both biotic and abiotic contributions) is a fundamental precondition to the existence and vitality of the resource, as in rivers and streams. To address complex and dynamic issues and manage large transboundary social-ecological systems and their resources, collaborative institutional structures that unite governmental, private, and non-governmental organizations, as well as individuals into both formal and informal arrangements is needed (Powell, 2010).

Arguments have been made that institutional scholarship has become overly concerned with explaining institutions and institutional processes, notably at the level of the organizational field, rather than with using them to explain and understand organizations (Greenwood et al., 2014). There is considerable fluidity and confusion on the boundaries between institutions and organizations (North, 1990; Edquist and Johnson, 1997). Organizations are created with purposive intent in consequence of the opportunity set resulting from an existing set of constraints, and in the course of attempts to accomplish their objectives are a major agent of institutional change (North, 1990). Furthermore, organizations are embedded in an institutional context of socio-cultural ideas and beliefs that prescribe appropriate and socially legitimate ways of doing things and are therefore subject to institutional influences in either positive or negative ways (Greenwood et al., 2014). Lastly, organizations are formal structures with an explicit purpose and they are consciously created, whereas, institutions may develop spontaneously and are often not characterized by a specific purpose (Edquist and Johnson, 1997).

In the United States, new organizational systems specifically for river restoration and stewardship have begun proliferating over the past couple of decades (Lant, 2003). The primary drivers have been the necessity of compliance with the Endangered Species Act of 1979 and public mobilization of political support to preserve the ecosystem services the river provides. With the creation of such organizations also comes the question, can these organizations sustain themselves over the long-term? What would keep them going despite changes occurring internally and disturbances from the environment externally?

We examine the effect of both biophysical and institutional disturbances on organizations through a study of the extent of attitudinal diversity in response to organizational agendas.
Attitudinal diversity is defined as the varying attitudes around the yearly program agendas, ranging from supportive to critical. The cases include the Upper Colorado River Endangered Fish Recovery Program (UCREFRP), and the Lower Colorado River Multi-Species Conservation Program (LCR-MSCP). For the purposes of this study, the two programs represent a polycentric organizational construct with multiple organizations working toward a common goal. The study answers the following research questions:

(1) What are the impacts of environmental disturbances on restoration governance systems?

(2) What role does intra-organizational diversity play in fostering organizational resilience and what are its effects?

Because a disturbance-response framework is utilized in the conceptualization of organizational resilience, a characterization of the types of disturbances hitting the systems being studied is detailed. Disturbances, in an ecological sense, are defined as any relatively discrete event in time that disrupts ecosystem, community or population structure and changes resources, substrate availability, or the physical environment (Pickett and White, 1985). There has been a growing emphasis in socialecological systems science that complex dynamics often lead to unexpected outcomes with long-term effects. The disturbances that occur in social-ecological systems can be sudden events that are large in magnitude and/or infrequent, termed as "pulse" dynamics or extensive, pervasive and subtle change termed as "press" dynamics (Collins et al., 2011). Furthermore, institutional disturbances as utilized in this study can be those rooted in broad socio-cultural norms and values, legislative and regulatory measures or market factors, while the biophysical disturbances refer to cases of episodic "hydrologic" drought, climate change and continuing chronic "megadrought" as well as the presence of invasive species (Young, 2010).

\section{ORGANIZATIONAL RESILIENCE CONCEPTUALIZED}

Organizational resilience, in essence, is defined as the maintenance of positive adjustment under challenging conditions (i.e., shocks, disruptions, stresses, and strains) such that the organization emerges from those conditions strengthened and more resourceful (Vogus and Sutcliffe, 2007). In other words, the process of "resiling" in the face of ongoing strain and discrete jolts is due to the presence of latent resources that can be activated, combined and recombined in new situations as challenges arise. The implication is that resilience relies upon past learning and fosters future learning, but also exists independently of learning and is embedded within a broader store of constitutive capabilities or endowments (Vogus and Sutcliffe, 2007). These characteristics correspond with the three dimensions of organizational response resilience not only to current issues (concurrent action) or the past (reactive action), but also to the future (anticipatory action) (Duchek, 2014). Furthermore, past learning speaks to a reliance on organizational memory that is posited to consist of mental and structural 
artifacts that have consequential effects on performance (Walsh and Ungson, 1991).

Anticipatory capabilities refer to the ability of organizations to detect critical developments and to adapt proactively to future changes before they happen. This involves activities such as looking for signals or environmental scanning, which is a process of acquiring information in preparation for inevitable surprises (Duchek, 2014). Both anticipatory learning and organizational memory are rooted in actors' various capabilities, knowledge skills, processes, and routines that facilitate access to resources (Duchek, 2014).

Capabilities for durability or coping capabilities, which is another feature of organizational resilience, refers to the endowments actors possess prior to adversity that shape their capacity for positive adjustment. Endowments facilitate resilience by enabling adaptability and may include financial capability, cognitive capability, behavioral capability, emotion-regulation capability, and relational capability endowments (Williams et al., 2017). This speaks to resilience at the organizational level referring to an organization's ability (embodied in the existence of resources, ideologies, routines and structures) to absorb a discrete environmental jolt and restore prior order (Williams et al., 2017). The authors also speak of an extension of this concept in the systems tradition to include dynamic processes rooted in relational patterns between actors that may affect a reorganization following a disturbance, while still retaining essential structures, functions and identity.

Adaptive capability is strongly linked to strategic actions that aim toward a reconfiguration of organizational resources, competencies and routines to meet demands and opportunities in a changing environment (Kaehler et al., 2014). Adaptive capability can be associated with multiple organizational identities, which in public organizations can take the form of networks, projects, hierarchies and so on. As time goes by, each unit learns to be better at what they are doing and grow into stronger identities (Aagaard, 2012). Adaptive capability can be studied through the processes of integration (involving cultural consensus and clarity), differentiation (involving subcultures and islands of clarity), and fragmentation (involving rituals loaded with ambiguity; Aagaard, 2012).

Laughlin (1991) argues that organizations, for possible psycho-social reasons are naturally change resistant, with a strong tendency to "inertia" and will only change when forced, "kicked" or disturbed into doing something. However, once disturbed, he argues that the track which the disturbance takes through the organization and the degree of transformation it will generate in the pathway it follows will differ over time and across different organizations based on certain organizational characteristics. These organizational characteristics comprise three distinct elements: sub-systems (tangible elements such as buildings, people, machine, etc.), design archetypes (intangible structures, accounting processes, and systems) and interpretive schemes (core values, norms, culture, beliefs, rules, missions statements, etc.), with the less tangible elements being more central to organizational functioning (Laughlin, 1991).

Laughlin (1991) described four pathways that characterize organizational responses to environmental disturbances:
(1) Rebuttal-the environmental disturbance is externalized and/or deflected in an attempt to protect and maintain the prevailing organizational equilibrium. These involve negligible changes to the sub-systems, design archetypes, and interpretive schemes.

(2) Reorientation-If a disturbance cannot be rebutted by adjusting the internal organizational infrastructure, it is accepted and assimilated within the workings of the organization in such a way that it is absorbed by interpretive schemes, with lasting change to the nature of the design archetype and some elements of tangible sub-systems.

(3) Colonization-It is forced upon the organization by those who have power over the design archetype and its resources, leading to major shifts that create lasting and fundamental change in both the visible and invisible elements.

(4) Evolution-Also involves major changes to the organization and its interpretive schemes, with the difference being, the change is chosen and accepted by all organizational participants freely, without coercion. It leads to a change in the current interpretive scheme which will also drive changes in the design archetype.

Intrinsic to these models is the distinction between the first and second-order change precipitated by environmental disturbances that has parallels to single and double-loop learning (Argyris and Schon, 1978). First-order rebuttal and reorientation pathways are responses to morphostatic change (making things look different while remaining the same) and are therefore termed "transitions," whereas second-order changes including colonization and evolution are morphogenetic (penetrating deeply into the genetic code) and represent "transformations."

What kind of organizational response is invoked and what pathway is chosen is dependent on the extent of the environmental disturbance, which can range from low to high. Figure 1 shows the organizational response patterns in relation to environmental disturbances (Tucker, 2013).

\section{Conceptualizations of Diversity}

Diversity in social-ecological systems comes in different shades and sizes including functional diversity, livelihood diversity, cultural diversity, and the relative size or power of these groups. Diversity and redundancy in social-ecological system components such as species, landscape types, knowledge systems, actors, cultural groups, or institutions provide options for responding to change and disturbance and for dealing with uncertainty and surprise (Folke et al., 2003; Ostrom, 2005; Kotschy et al., 2015; Schoon et al., 2015).

Diversity is often used to describe the distribution of differences among the members of a unit with respect to a common attribute. Diversity and heterogeneity has often been used interchangeably, though heterogeneity implies interactively integrating different entities whereas diversity implies divergence (Schoon et al., 2015; Shavit et al., 2016). There has been no consensus in the literature on the effect of heterogeneity and group size on collective action due to lack of uniform conceptualization of these factors (Poteete and Ostrom, 2004). For instance, one study predicted that diversity in teams would 


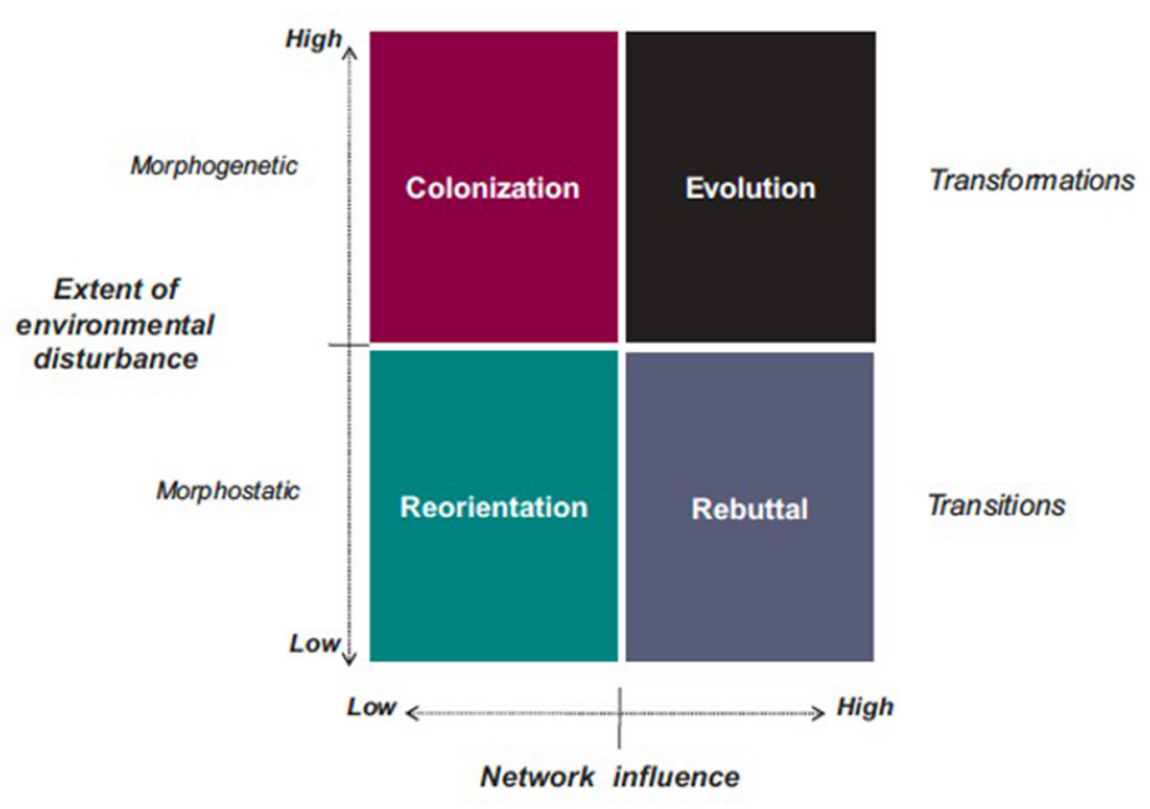

FIGURE 1 | Reconstructed model of Laughlin's organizational change pathways (Tucker, 2013).

lead to less liking and lower affective outcomes (Byrne, 1971; Milliken and Martins, 1996); another study found that declining levels of organizational commitment occurs when diversity in gender and race increased with no negative effects for age, education and organizational tenure (Tsui et al., 1992); a third study found that heterogeneity in age and tenure was positively related to turnover, but tenure diversity has also been positively related to internal task processes and finally that functional diversity was positively related to external communication but the direct effect of diversity on team performance was negative (Ancona and Caldwell, 1992).

Theoretical and empirical research suggests that response diversity in combination with functional redundancy is important in maintaining ecosystem services in the face of disturbance and ongoing change and increasing system resilience (Kotschy et al., 2015). Typologies of organizational diversity can reflect separation: team members hold opposing positions on a task- or team-relevant issue; variety: team members bring a multiplicity of information sources to bear on an issue; or disparity: one member of the team is superior to the other members in resources or status (Harrison and Klein, 2007; Stirling, 2007).

The idea of diversity as separation is rooted in similarity attraction and social categorization theories which argue that greater similarity yields higher levels of cooperation, trust and social integration. Conversely, members who differ markedly on a continuum will experience low cohesion, high conflict, high rates of withdrawal and poor performance. Diversity has also been differentiated between task-related and relations-oriented attributes. Task-oriented attributes are related to knowledge, skills, abilities needed in the workplace (e.g., function, tenure, and education) and relations-oriented attributes include demographics such as age, sex, race, and ethnicity that shape interpersonal relationships but do not have a direct bearing on performance (Jackson et al., 2003).

Furthermore, task-related or functional diversity also has multiple conceptualizations including as dominant function diversity (the diversity of functional experts on a team), intrapersonal functional diversity (the aggregate functional breadth of team members), functional background diversity (the degree of difference in the complete functional backgrounds of team members), and functional assignment diversity (diversity in the functional assignments of team members). Different forms of functional diversity can have different implications for team processes and performance (Bunderson and Sutcliffe, 2002). How diversity is measured within groups and between groups varies based on the conceptualization and attributes selected. Because functional diversity is associated with differences of opinion and perspective, it is possible that these differences may result in less effective performance (Bunderson and Sutcliffe, 2002).

Diversity in organizational work units has, at its core, heterogenous perspectives, different cognitive mindsets, and creativity (Duchek et al., 2020). Building on conceptualizations of diversity in the previous section, we propose utilizing attitudinal diversity as a measure of organizational resilience. The prevalence and extent of attitudinal diversity will yield insights into key resilience capabilities outlined in section Organizational Resilience Conceptualized-anticipatory capabilities, coping capabilities, and adaptive capabilities.

\section{Characterizing Attitude}

The origins of research on attitudes and behavior can be traced to the theory of reasoned action (TRA; Fishbein and Ajzen, 1975). 
This model has been used to predict individual behavior based on pre-existing attitudes and behavioral intentions, however, there were shortcomings identified in the model, specifically in the distinction between goal intention and behavioral intentions (Sheppard et al., 1988). Whenever the performance of some action requires knowledge, skills, resources or others' cooperation, or necessitates overcoming environmental obstacles, the model falls short in application (Sheppard et al., 1988).

The theory of planned behavior (TPB; Ajzen, 1988, 1991) was developed as an extension of applicability of the TRA by incorporating explicit consideration of perceptions of control over performance of the behavior as an additional predictor of behavior, and linking behaviors to goal attainment (Conner and Sparks, 2020). While perceived behavioral control added significantly to the prediction of intentions in TPB (Ajzen and Madden, 1986), one of the major limitations of the applicability of these models is that they have tended to rely on self-reporting and are therefore subject to self-presentational biases (Armitage and Conner, 2001).

Eagly and Chaiken (1993) offer an umbrella definition of attitude as including three essential features-evaluation, attitude object, and tendency. Evaluation refers to all classes of evaluative responding, whether overt or covert, or cognitive, affective or behavioral. Evaluative responding is directed to some entity or thing that is its object, also known as attitude object. The authors' definition places attitudes inside the mind of the individual. Attitude objects may be abstract or concrete. An individual's past experience established a tendency to respond with some degree of positivity or negativity to an attitude object. Tendency does not imply the residue of past experience exists on an enduring basis or on a temporary basis. In psychology, the term state has been used to imply temporariness, while disposition implies greater permanence (Eagly and Chaiken, 2007).

Attitude measurement can be undertaken in a variety of different ways in the social psychology realm. These include implicit or indirect attitude measures for evaluating the role of unconscious bias, such as sequential priming, response inference tasks, affective priming, semantic priming, or the Implicit Association Test to name a few examples (Gawronski, 2007). These are different from the above-mentioned explicit or direct attitude measures based on self-reported questionnaires that infer conscious assessment (Payne et al., 2008). However, the widespread assumption that explicit evaluations reflect conscious attitudes while implicit evaluations reflect unconscious attitudes has been critiqued based on a review of available evidence which suggests that a lack of source awareness is not a distinguishing feature of implicit attitudes and that there is no evidence that people lack conscious awareness of implicit attitudes (Gawronski et al., 2006).

\section{THE COLORADO BASIN CASE STUDIES: OVERALL INSTITUTIONAL CONTEXT}

The seven basin states came together in 1922 in order to resolve the equitable division and apportionment of the use of the waters of the Colorado River system. The result of this was the apportionment of 7.5 million acre-feet per year equally to the Upper and Lower Basin states, respectively, for exclusive beneficial consumptive use, with Mexico getting the surplus over and above the aggregate of the quantities specified. The requirement of the Colorado River Compact was that Upper basin states not cause the river flow at Lee's Ferry to be depleted below 75 million acre-feet for any period of 10 consecutive years nor withhold water to Lower basin states.

Later amendments to the agreement included the 1928 Boulder Canyon Project Act authorizing the construction of the Hoover Dam, the 1944 Mexican Water Treaty which allocated 1.5 million acre-feet to Mexico, and the 1948 Upper Basin Compact which solidified the water allocation amounts between the Upper Basin states. Additionally, the Colorado River Storage Project of 1956 authorized the construction of Glen Canyon, Flaming Gorge, Navajo and Curecanti dams for river regulation and power production as well as for irrigation and other uses. The Colorado River Basin Project Act of 1968 authorized the construction of a number of water development projects in both the upper and lower basins, including the Central Arizona Project (CAP). It also made CAP water supply subordinate to California in times of water shortage. Finally, Minute 242 of the US-Mexico International Boundary and Water Commission of 1973 required the United States to take actions to reduce the salinity of water being delivered to Mexico at Morelos Dam. This resulted in the Colorado River Basin Salinity Control Act of 1974 which authorized desalting and salinity control projects including the Yuma Desalting Plant, to improve Colorado River quality (USDOI, 2008).

The main problem arising out of these was that these amounts were overallocations based on measurements taken at Lee's Ferry during greater than average wet years. Among the Upper Basin states, Colorado has senior rights with 3.9 million acre-feet allocated, Utah -1.7 million acre-feet, Wyoming -1.0 million acre-feet, and New Mexico -0.85 million acrefeet. The Lower Basin states includes California as a senior rights state with 4.4 million acre-feet, followed by Arizona at 2.85 million acre-feet and finally, Nevada with 0.30 million acrefeet (CRS, 2020). Another problem is that since implementation of the 1974 Salinity Control Act, measures have been put in place to reduce the annual salt load of the river by more than 1.3 million tons. The salinity concentrations at Hoover, Parker and Imperial dams has been reduced by more than 100 $\mathrm{mg} / \mathrm{l}$. However, even with these efforts, the quantified damages to U.S. users are still $\sim \$ 454$ million per year, with projected damages to increase to $\$ 574$ million per year by 2035 if the Program does not continue to be aggressively implemented (Keeler, 2017).

\section{Institutional Context-Upper Colorado River Endangered Fish Recovery Program}

This program was developed in 1988 as part of a cooperative effort that involved many of the agencies and organizations that have an interest in how the Upper Colorado River Basin and its resources are managed. These include the States of 
Colorado, Utah and Wyoming, the US Bureau of Reclamation, the US Fish and Wildlife Service (US FWS), water development interests and environmental organizations. The main impetus was to balance water development and also ensure compliance with the Endangered Species Act that came into effect in 1979. The goals of the program were to bring back four native fish species that were endangered due to intensive water development activities. These species include the humpback chub (Gila cypha), bonytail chub (Gila elegans), the Colorado pikeminnow (Ptychocheilus Lucius), and the razorback sucker (Xyrauchen texanus).

The States of Colorado, Utah, and Wyoming determine how the river system's water resources are developed and to fulfill legal requirements that could constrain water resources development. The program is organized in a hierarchical structure with the Program Director overseeing the Implementation Committee whose primary responsibility is to interface with the US Congress and the Secretary of the Interior; the Management Committee which oversees program implementation and decision-making; the Biology Committee, the Water Acquisition Committee and the Information and Education Committee who oversee the science, business, and communication aspects of the program respectively.

\section{Institutional Context-Lower Colorado River Multi-Species Conservation Program}

After critical habitat was listed for the razorback sucker and bonytail in 1994, representatives from agencies responsible for water and power management along the lower Colorado River met to discuss a comprehensive plan to conserve native species and their habitats in compliance with environmental compliance under the Endangered Species Act. In April 1997, the USFWS issued a Biological and Conference Opinion to Reclamation covering routine operations and maintenance activities along the Colorado River from Lake Mead to the Southern International Boundary (SIB). That biological opinion served two purposes: it provided Reclamation with Endangered Species Act compliance through 2002 (it was subsequently extended through 2005) and called for stakeholders along the lower Colorado River to develop and implement the Lower Colorado River MultiSpecies Conservation Program (LCR MSCP). On April 4, 2005 Department of the Interior Secretary Gail Norton and representatives from agencies within Arizona, California, and Nevada signed documents to implement the LCR MSCP.

The program area extends over 400 miles of the lower Colorado River from Lake Mead to the southernmost border with Mexico, and includes lakes Mead, Mohave, and Havasu, as well as the historic 100-year floodplain along the main stem of the lower Colorado River. The HCP calls for the creation of over 8,100 acres of habitat for fish and wildlife species and the production of over 1.2 million native fish to augment existing populations. The plan will benefit at least 27 species, most of which are state or federally listed endangered, threatened, or sensitive species. The Bureau of Reclamation is the implementing agency for the LCR MSCP. Partnership involvement occurs primarily through the LCR MSCP Steering Committee, currently representing 57 entities, including state and Federal agencies, water and power users, municipalities, Native American tribes, conservation organizations, and other interested parties, which provides input and oversight functions in support of LCR MSCP implementation. Program costs are evenly divided between the Federal government and non-federal partners.

\section{METHODS}

Diversity analysis in organizational and management literature has been heavily reliant on horizontal surveys and questionnaires that elicit people's attitudes and reactions to certain issues (Miller et al., 1998; Simons et al., 1999; Kilduff et al., 2000; Ricardo, 2000). Some studies rely on focus group discussions and interviews with organizational personnel (Mor Barak et al., 1998; Gilbert and Ivancevich, 2000; McIntosh and Morse, 2015). Fiol (1994) used codes to measure consensus building around the content and framing of meanings to determine how diverse interpretations fostered innovation and collective learning. We use a similar method to analyze attitudinal diversity based on content analysis.

The choice of the two cases was the result of a combination of various factors including the geographic proximity of the systems being studied, the availability of appropriate program documentation for coding, the ease of initiating stakeholder interviews to supplement archival analysis and a specific focus on institutions for river restoration. A few other case studies were considered but did not meet one or more of these criteria and, therefore, were excluded from the analysis.

For the purposes of analysis, we utilized archival material from the program websites, specifically the meeting minutes for every year of the existence and functioning of both the UCREFR and LCR-MSC programs. The number of meetings over the years has varied somewhate with the UCREFRP having an average of two meetings per year and the LCR-MSCP had an average of three meetings per year. The LCR-MSCP generally conduct deliberations around a water-year from October to September. For the purposes of this study, we have grouped deliberations into a calendar year, instead to ensure consistency in cross-case comparisons. The meetins are conducted each year from program inception The meeting is generally called by the Implementation or Steering Committee Chair who is elected by common vote every few years, from one of the participating agencies. The length of the meeting minutes are variable, with some being short and some long duration, depending on issues on the agenda. Because of the dispersal of the meetings, a significant number of them are carried out remotely, with some being carried out at specific chosen locations depending on upper or lower basin region.

We coded the meeting minutes of the programs using defined codes for assessing the diversity of attitudes present in each meeting, ranging from positive to negative, including neutral expressions. The UCREFRP has a much richer and more extensive dataset than the LCR-MSCP, which is quite sparse. The datasets used are available at https://osf.io/j36ry/. Assessment of attitudinal diversity is seen as a variance of views/opinions/articulations around each meeting agenda and 
the goal and task interdependence for that period. The meeting agenda is taken as a baseline around which attitudinal variation is measured. Attitudes are divided into four categories for a more fine-grained analysis-Supportive, Clarifying, Conditional, and Critical.

A "Supportive" code was assigned to text entries where all statements in a discussion on the agenda that are positive or supportive of the agenda based on linguistic qualifiers that include but are not limited to "should be supported/accepted," "should not be rejected," "suggested/asked that," "proposed that," "....if deemed necessary," "agreed that" and so on.

A "Clarifying" code was assigned to text entries where all statements in a discussion on the agenda are seeking further information or clarification on the topic and/or questioning issues further but have not yet expressed a marked positive reaction. Linguistic qualifiers include but are not limited to "asked if/why...," "expected that...," "responded that...," "noted/stated that...." "clarified that" and so on. This code is viewed as neutral because it illustrates the general questionanswer and clarification that is sought in any discussion of the agenda topics.

A "Conditional" code was assigned to text entries where all statements in a discussion on the agenda that emphasize the fulfillment of certain conditions before the theme of the agenda is accepted. Since the tone of the code is more of a conditional acceptance with negative connotations, it is taken as a negativeleaning attribute. Linguistic qualifiers include but are not limited to "before a decision is made..." "what is gained/intended by...?", "if...can be changed/modified/developed/excluded...," "support, but...." and so on.

A "Critical" code was assigned to text entries where all statements in a discussion on the agenda that are critical to/of the agenda. This code is the most negative-leaning in tone. Linguistic qualifiers include but are not limited to "not yet convinced....", "...could make things more difficult/challenging," "concerned about/expressed concern about...," "reconsider, pending...," and so on.

Intercoder reliability rating was conducted on $30 \%$ of the documents that were analyzed using the guidelines for computing inter-reliability rating (Hallgren, 2012). A total of 35 segments, taken from random document sections, were analyzed by the second coder independently. The total code numbers for each attribute for each segment were entered into a spreadsheet and intraclass correlation (ICC) calculated for the four main attitudinal diversity attributes before the codes were reconciled through discussion. ICC was chosen because the purpose was to assess the consistency and reproducibility of the measurements made by independent coders as some codes were clear-cut and some more ambiguous and contextual. The ICC was run on SPSS using a two-way mixed effects model with an absolute agreement definition. Table 1 below lists the descriptive statistics for ICC for each of the four main attitudinal variable categories.

Finally, a sample of codes are displayed for each category of codes to show the best examples of coding that fall under that category, in the table in Appendix A. In other words, a small sample of those codes that clearly fall into one category based on the operational definitions of that category are listed to provide a
TABLE 1 | Descriptive statistics for attitudinal variable sample.

\begin{tabular}{lcccc}
\hline & Supportive & Clarifying & Conditional & Critical \\
\hline Cronbach's Alpha & 0.914 & 0.828 & 0.756 & 0.744 \\
Std dev coder A & 3.02 & 3.56 & 1.28 & 1.24 \\
Std dev coder B & 2.85 & 3.41 & 1.31 & 2.34 \\
Variance & 0.015 & 0.069 & 0 & 0.216 \\
Inter-item correlation & 0.843 & 0.707 & 0.608 & 0.714 \\
ICC average measures & 0.915 & 0.830 & 0.761 & 0.721 \\
95\% Cl lower bound average & 0.833 & 0.664 & 0.524 & 0.446 \\
measures & & & & \\
95\% Cl upper bound average & 0.957 & 0.914 & 0.880 & 0.860 \\
measures & & & & \\
\hline
\end{tabular}

clearer depiction of how the codes were used. Definite examples of statements are those that clearly depict linguistic qualifiers for a particular category. Ambiguous examples are coded based on the context of the discussion about the agenda. The latter category is why, for example, a linguistic qualifier such as "countered" would be taken as supportive because the countering is in support of the agenda rather than critical of it or a linguistic qualifier like "said that" would fall into a condition category rather than a clarifying one because it is conditional on a particular action.

\section{RESULTS}

Figures 2, 3 shows the temporal patterns of distribution of attitudinal diversity for the UCREFRP and LCR-MSCP, respectively. Both programs have their inception in a desire to avoid jeopardy or financial penalties associated with the impacts of continued water development activities on critically endangered fish species as well as on incidental take from recreational fishing activities. Attitudinal diversity variation tends to lessen over time in the UCREFRP case. We observe that critical and conditional attitudes were more prevalent over the first 10-year period starting from 1988 and lessened after that. The 1994-1997 period was not showing success in terms of native fish protection and there was concern about further investment until the situation showed improvement. Overall, there is growing convergence toward agreement based on the higher supportive and clarifying attitudes around the agenda issues and a diminution of critical attitudes over time.

It is evident that the period from the inception of the UCREFRP to 2000 showed a greater attitudinal diversity than the period post-2000 to present. The years 2008 and 2018 show absence of good data for analysis and are discounted. The period 1988-1998 was the period when the most important issues such as institutional membership, native fish recovery, non-native fish management and capital investment projects were closely discussed with variable success over the period. The 1994-1997 period depicts a period of setbacks in program goal achievements and resulted in increased efforts to incorporate science-based approaches to flow management to increase propagation and survival of listed native fish species. The period from 1988 to 2000 therefore signifies a phase when consensus was less easily achieved due to implementation challenges. However, post-2000 


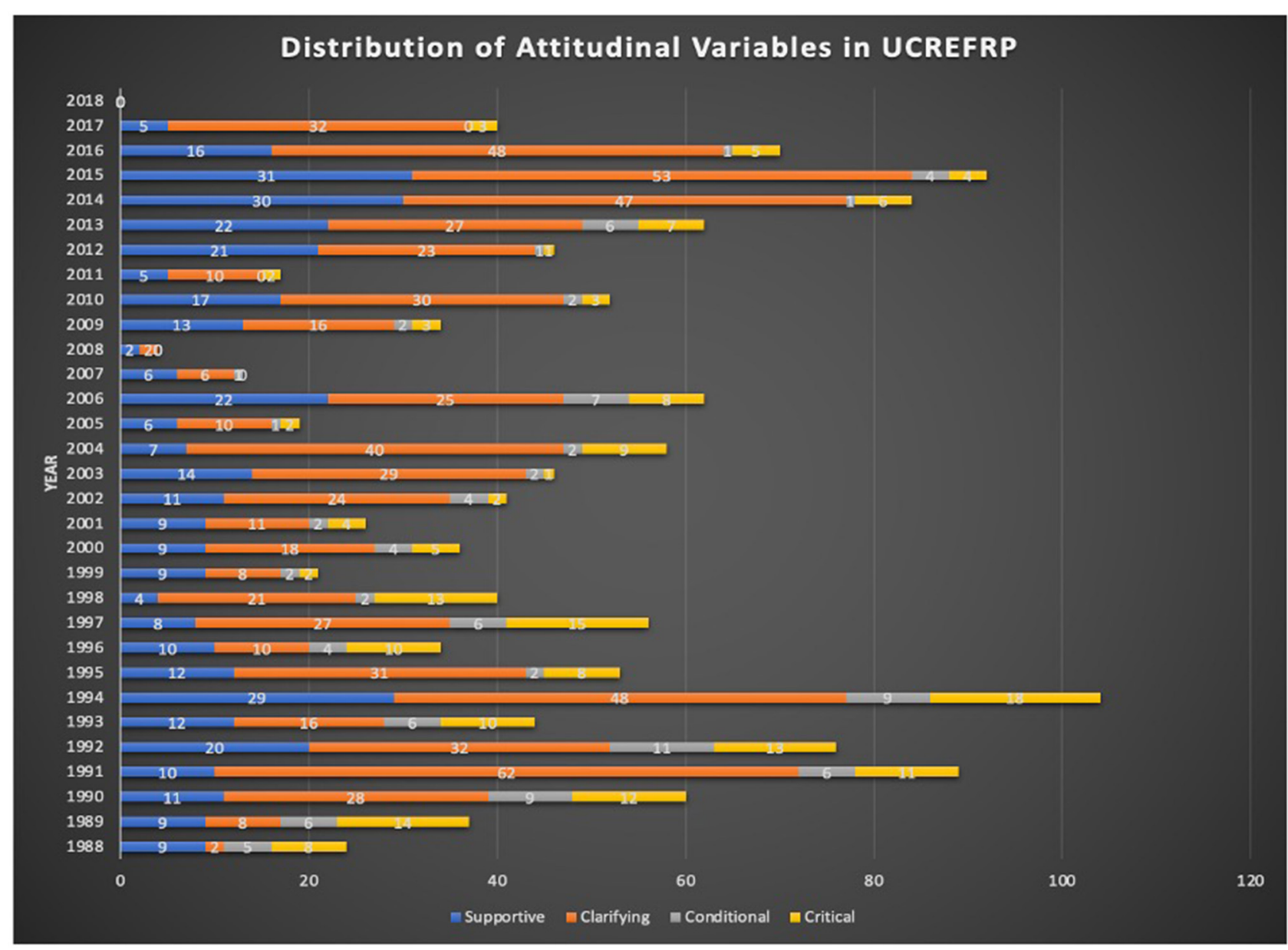

FIGURE 2 | Trends in attribute variables for UCREFRP.

there appears to be greater positive responses with the agreement being higher.

The LCR-MSCP does not have sufficient and consistent data over time. But what can be observed from Figure 3 is that critical attitudes have persisted or occurred at discrete intervals over time. This is supported by evidence that details that a building dissension around key program goals resulting in legal settlement of a water right dispute centered around acquiring water leases for fish conservation (Arizona Department of Water Resources vs. Mohave County, 2015). During the period 2009-2010, the acquisition of land for habitat construction was being considered, toward housing listed endangered species including the Southwestern Willow Flycatcher. One of the potential land acquisitions considered was Planet Ranch, which is located $\sim 20$ miles east of Parker, Arizona upstream of the Bill Williams River National Wildlife Refuge. It was a site owned by Freeport McMoran Mineral Corporation. The land is 3,418 acres with 5,549 acre-feet of water rights attached to it. Initial discussions merely kept the proposal under consideration.

When the acquisition became more viable, Mohave County Water Authority and the City of Bullhead registered opposition to the acquisition on grounds that there was lack of involvement of the local government in the final agreement, particularly in relation to settlement provisions and water rights transfers. The LCR-MSCP has arbitration measures where the Steering Committee calls for a deciding majority vote on an issue if agreement cannot be reached through discussion. This vote found overwhelmingly in favor of acquisition of Planet Ranch for the program. However, the matter was further taken to the courts with the final decision being made in favor of the Program. In December 2015, LCR-MSCP acquired a lease for Planet Ranch to be used as a conservation area. There was a gradual build-up of concern and then opposition until the 2013-2014 period when the acquisition was brought to the table for implementation.

Table 2 below illustrates the various environmental disturbances that have affected the two organizations over time, how the organizations responded; how attitudinal diversity mediates the leveraging of organizational resilience capabilities to these disturbances is discussed in the following section. Environmental disturbances are characterized as either press or pulse events and are either institutional or biophysical in nature. Press disturbances are long-term disturbances with long-term 


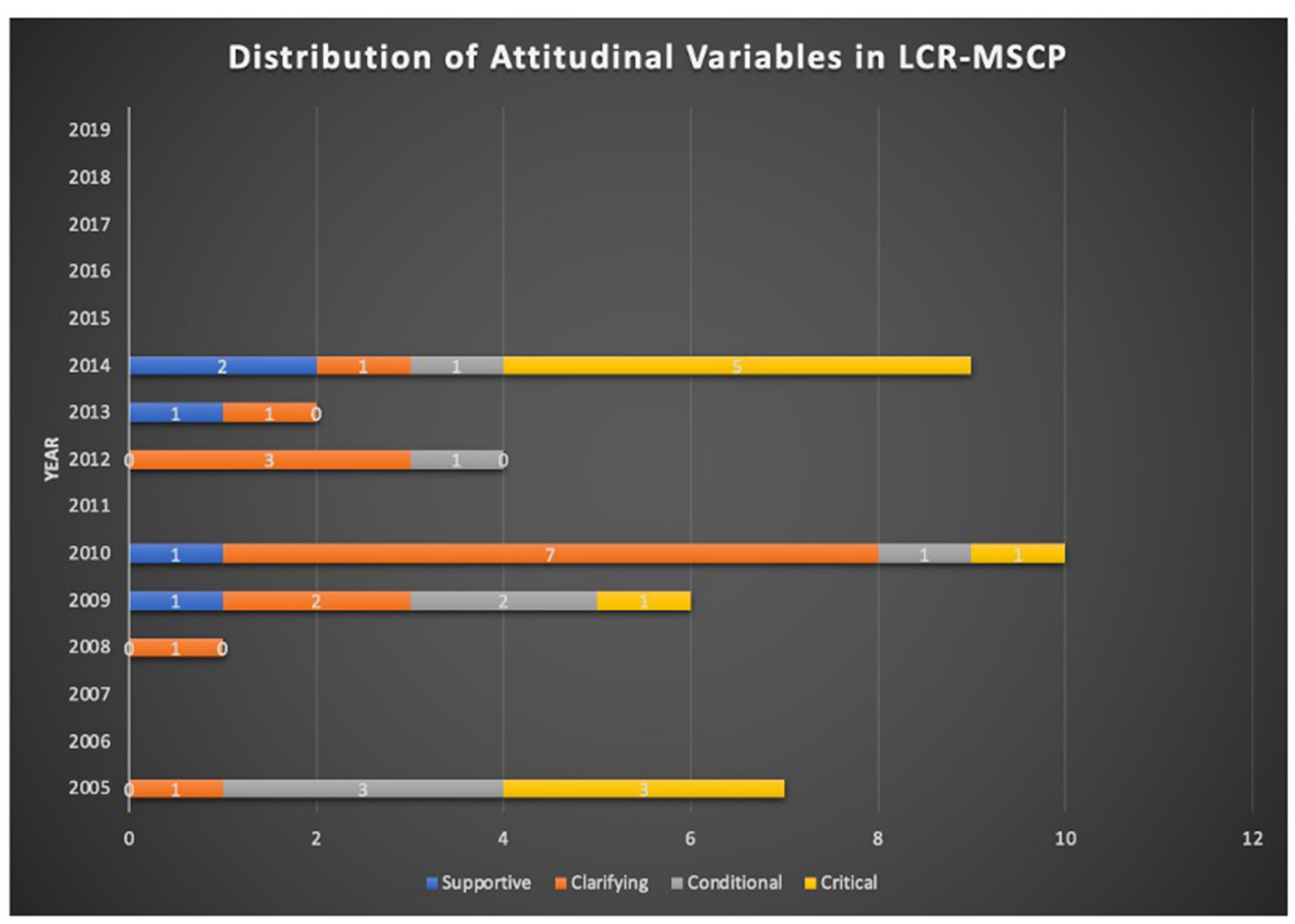

FIGURE 3 | Trends in attribute variables for LCR-MSCP.

impacts, while pulse disturbances are temporary in nature and while they may cause substantial impacts, there is potential for the system to rebound or recover. Institutional disturbances can take the form of broad socio-cultural norms and values, legislation and regulatory policies and market factors, while biophysical disturbances include drought (both episodic and chronic), climate change and the presence of invasive species.

\section{DISCUSSION}

This section is organized into three parts. The first part concisely discusses the links between attitudinal diversity and organizational resilience capabilities and how this process has been operationalized in the study. The second part describes the role of attitudinal diversity in organizational responses to institutional disturbances and how resilience is displayed, while the third part discusses the same in the context of organizational responses to biophysical disturbances.

\section{Role of Attitudinal Diversity in Building Resilience Capabilities}

Anticipatory resilience capabilities can be operationalized by six factors including goal-directed solution seeking, risk avoidance, critical situational understanding, role dependence, information source reliance, and resource access (Mallak, 1998). Research on top management teams has found that a higher magnitude of turnover in membership tended to have a broader scope of environmental scanning, both within and across sectors, as such changes bring in new information sources and environmental scanning practices (Cho, 2006). The attitudinal diversity to institutional press events for both UCREFRP and the LCRMSCP involved processes of inclusion-exclusion of decision makers, delegations of authority and goal clarifications. With the necessity of ESA compliance, both recovery programs expanded to include federal, state and local wildlife agencies as well as environmental groups. The programs have thus been able to rely on a wide range of organizational information sources and practices to anticipate environmental risks of take (water use). Furthermore, anticipation of the long-term nature of the programs, has resulted in successive extension of UCREFRP mandates to future years, which also includes the provision of committed funding from Congress.

Coping capabilities generally involve sense-making and problem solving. Diversity plays an important role in sense-making through construction of a greater variety of interpretations for adverse situations and a more precise basis for decision-making (Duchek et al., 2020). Dealing with complex crises requires the knowledge and interaction of different people and creativity in making use of limited resources. The attitudinal diversity during biophysical press and pulse events has been low. However, a more in-depth analysis of the UCREFRP and LCR-MSCP program responses to these 
TABLE 2 | Organizational responses to environmental disturbances, attitudinal diversity and the leveraging of different resilience capabilities in response.

\begin{tabular}{|c|c|c|c|c|c|c|}
\hline $\begin{array}{l}\text { Environmental } \\
\text { disturbance }\end{array}$ & Type & Region & Year & Organizational response & Attitudinal diversity & $\begin{array}{l}\text { Resilience } \\
\text { capabilities }\end{array}$ \\
\hline \multirow[t]{2}{*}{$\begin{array}{l}\text { Enforcement of } \\
\text { endangered species } \\
\text { act, } 1978\end{array}$} & Institutional press & Upper basin & 1987-present & $\begin{array}{l}\text { UCREFRP formation with } \\
\text { greater vertical nested } \\
\text { polycentricity to mitigate } \\
\text { financial or legal penalties for } \\
\text { non-compliance with USFWS } \\
\text { as greater authority }\end{array}$ & $\begin{array}{l}\text { Resting on } \\
\text { inclusion-exclusion } \\
\text { aspects of program } \\
\text { participants and pathways } \\
\text { to achieving program } \\
\text { goals. }\end{array}$ & Anticipatory \\
\hline & & Lower basin & 2005-present & $\begin{array}{l}\text { LCR-MSCP formation with } \\
\text { greater horizontal polycentricity } \\
\text { to mitigate financial and/or } \\
\text { legal penalties for } \\
\text { non-compliance with } \\
\text { Reclamation and USFWS as } \\
\text { co-leads but Reclamation } \\
\text { having greater authority }\end{array}$ & $\begin{array}{l}\text { Resting on designation of } \\
\text { authority in the } \\
\text { decision-making Steering } \\
\text { Committee and inclusion } \\
\text { of program participants }\end{array}$ & Anticipatory \\
\hline \multirow[t]{2}{*}{$\begin{array}{l}\text { Weakening of ESA } \\
\text { regulations }\end{array}$} & Institutional pulse & Upper basin & 2017-2020 & $\begin{array}{l}\text { Based on 5-year Species } \\
\text { Status Assessments (SSA), the } \\
\text { program (with approval from } \\
\text { US Fish and Wildlife Service) } \\
\text { proposed downlisting of } \\
\text { humpback chub and } \\
\text { razorback sucker species from } \\
\text { endangered to threatened in } \\
2018\end{array}$ & $\begin{array}{l}\text { Agreement on further } \\
\text { extension of Program post } \\
2023 \text { because of } \\
\text { continued need for } \\
\text { aggressive non-native fish } \\
\text { control which has not } \\
\text { been successful. }\end{array}$ & $\begin{array}{l}\text { Anticipatory, } \\
\text { adaptive }\end{array}$ \\
\hline & & Lower basin & 2017-2020 & - & - & \\
\hline \multirow[t]{2}{*}{$\begin{array}{l}\text { Exceptional low flow } \\
\text { years }\end{array}$} & Biophysical pulse & Upper basin & $2002,2012,2018$ & $\begin{array}{l}\text { Implementing long-term } \\
\text { co-ordinated reservoir } \\
\text { reoperations with either one or } \\
\text { two spike flows depending on } \\
\text { severity of hydrologic drought. } \\
2018 \text { saw an unprededented } \\
\text { amount of collaboration and } \\
\text { cooperation in releasing } \\
\text { needed water to maintain } \\
\text { minimum flows to avoid } \\
\text { dangerously dry conditions in } \\
\text { key stretches. }\end{array}$ & $\begin{array}{l}\text { Wide-spread agreement } \\
\text { and discussion about the } \\
\text { details of proposed plans } \\
\text { and implementation } \\
\text { pathways. }\end{array}$ & $\begin{array}{l}\text { Coping, } \\
\text { adaptive }\end{array}$ \\
\hline & & Lower basin & 2012, 2018 & - & - & \\
\hline \multirow[t]{2}{*}{$\begin{array}{l}\text { Climate change, } \\
\text { megadrought, invasive } \\
\text { species }\end{array}$} & Biophysical press & Upper basin & 2000 - present & $\begin{array}{l}\text { Recognition that flow releases } \\
\text { might be subjected to } \\
\text { hydrologic limitations and not } \\
\text { endangered fish releases and } \\
\text { continued prioritization of } \\
\text { invasive species control efforts } \\
\text { through information and } \\
\text { awareness campaigns to } \\
\text { garner widespread public } \\
\text { support }\end{array}$ & $\begin{array}{l}\text { Agreement and discussion } \\
\text { around continued actions } \\
\text { and support for program } \\
\text { continuation }\end{array}$ & Coping \\
\hline & & Lower basin & 2005 - present & $\begin{array}{l}\text { Strategies to increase } \\
\text { coverage for flow reductions } \\
\text { due to appropriation below } \\
\text { Hoover, and Davis dams and } \\
\text { between Parker and Imperial } \\
\text { dams with focus on increasing } \\
\text { storage in Lake Mead }\end{array}$ & $\begin{array}{l}\text { Resting on acquisition of } \\
\text { water leases for } \\
\text { conservation areas that } \\
\text { threatened municipal } \\
\text { water rights and was } \\
\text { resolved via legal action }\end{array}$ & Coping \\
\hline
\end{tabular}

events suggest that operationalizing diversity in sense-making and problem-solving in response to biophysical press events required combined sense-making and problem solving with increased collaboration to achieve goals. A large part of organizational coping was illustrated by the inclusion of more actors (including private sector actors through short-term excess water lease agreements) to the table to provide a joint solution to maintaining environmental flows. As a short-term solution, 
these are sufficient. However, they do not address longer term creeping climatic impacts.

Adaptation capabilities refer to adjustments following a crises to produce a dynamic capability that is directed toward facilitating organizational change and long-term learning (Duchek et al., 2020). Attitudinal diversity facilitating adaptive capabilities can be observed in the UCREFRP in response to both institutional and biophysical pulse events. The low attitudinal diversity points to greater agreement in engaging in adaptive responses to these disturbances by leveraging greater collaboration and participation of private actors in crafting creative ways of maintaining environmental flows in response to extreme low flows. However, these short-term reactions do not indicate much reflexitivity or learning at any level. Diversity in perspectives forces organizations to avoid simple interpretations through constructive conflict and deeper discussions about actions to take (Haunschild and Sullivan, 2002). Incorporation of local and indigenous ecological knowledge is needed to increase the cognitive diversity that will be required to deal with creeping biophysical changes, as the presence of cognitive diversity has been found to produce high quality decisions when competencebased trust is present (Olson et al., 2007).

\section{Organizational Response to Institutional Disturbances}

The organizational responses to the institutional press event, referring to the continuous presence of the necessity of compliance with the ESA since the 1980's, reveal that there was a re-configuration of existing organizational architecture that mainly catered to water development, power generation, water supply and recreational interests. The ESA shifted the power dynamic from one of consideration only of water allocation and use to one of preservation of the base aquatic environment. The change occurring here was spurred mainly because of a desire to avoid the penalties of non-compliance due to water use and mitigating for incidental take of endangered species and reveals two main occurrences.

Firstly, the reconstitution of existing organizational architecture to include the US Fish and Wildlife Service (US FWS) as a major decision-maker, along with increased coordination between US FWS and the various State Game and Fish departments resulted in a prioritization of environmental concerns. This was compounded by the fact that environmental groups and non-governmental organizations that expressed an interest in participating in the reconstituted organization were included. This level of change was transformational in response to a high level of institutional press disturbance triggering a "colonization" response as depicted in Figure 1 where change is forced upon an existing organization leading to major shifts creating morphogenetic change.

Secondly, attitudinal diversity around initial discussions about whether or not to include participants reveal that there was hesitation and reticence about including key environmental agencies such as the National Park Service (NPS), during discussions about the UCR-EFRP formation. The main concern was the level of redundancy that the inclusions of all these stakeholders would entail. In terms of resilience capabilities, anticipation of legal penalties set the precedent for program formation and subsequent stakeholder inclusion. Similar anticipatory resilience capabilities also occurred during the formation of the LCR-MSCP.

Organizational responses to the institutional pulse events set in motion by the previous administration (2016-2020) reveal that, in the case of the UCR-EFRP, there was recognition that the complexity of the problems in managing for endangered species required an extension of the Program as well as pathways to assure longer-term funding security. The actions taken to ensure this reveal the exercise of anticipatory resilience capabilities. The low level of attitudinal diversity at this point in the program is a function of a convergence of values and attitudes over time, given the length of the program, as well as a build-up of trust between actors. Given the amount of financial capital invested in the program at this point as well as tangible investments in physical infrastructure to build hatcheries, achieve reservoir coordination as well as provide connectivity (in the case of the upper basin), there was no direct impact of this disturbance on the program.

In the case of the UCR-EFRP, the success of these program activities and a subsequent consideration of down-listing for species that had achieved self-sustainability, reveal adaptive resilience capabilities. The result of the down-listing would enable the organization to direct resources and capacities more efficiently toward continued management of listed species. This reveals a "reorientation" response as shown in Figure $\mathbf{1}$ and a morphostatic transition to more efficient organizational resource allocation and sustainability over the long term.

\section{Organizational Response to Biophysical Disturbances}

Biophysical pulse events that have affected the programs include extreme low flow years of 2002, 2012, and 2018 that could also be characterized as hydrologic drought years. The UCR-EFRP had been moving toward implementation of coordinated reservoir reoperations over the decade preceding 2002 to balance between water supply, augmentation, and provision of instream flows. These buffered to a significant part, the effects of the hydrologic drought on environmental flow provision and the maintenance of aquatic habitat for endangered species. Shortfalls in 2018 also resulted in increased collaboration and cooperation in the leasing and utilization of unused stored water to maintain environmental flows. As these decisions were undertaken during the second and third decade of program implementation, the establishment of trust and cooperation among actors accounts for low attitudinal diversity. The actions undertaken during these periods reveals the existence of considerable extant coping capabilities that were activated including relational, financial and behavioral capabilities as detailed in section Organizational Resilience Conceptualized. Furthermore, the increased collaboration in the 2018 drought year also illustrates adaptive capabilities that were introduced to bolster organizational resilience.

The biophysical press events are a compounded amalgamation of a continuing 21-year drought, other compounded effects of 
climate change, and the continued presence of invasive fish species. The UCR-EFRP has come to a stated recognition of the fact that future flow releases may be subject to hydrologic limitations and not endangered fish releases. However, continued efforts to contain invasive species presence through public recruitment by information and awareness campaigns also reveals that coping capabilities are being leveraged with widespread agreement. The LCRMSCP has followed a different strategy of increasing the coverage for flow reductions to include not just aquatic fish species but also riparian plant and bird species, and listed amphibian species as well as terrestrial species that occur in the covered areas. Attitudinal diversity data is sporadic but reveals the existence of conflicts with municipal water users due to the water leasing to sustain restored ecosystems. However, the strategy of increased coverage is a positive coping strategy given the path-dependent limitations of the program.

\section{CONCLUSION}

A discussion of the results reveals two main trends in organizational responses to disturbances and the resilience capabilities that are leveraged. The resilience capabilities in response to institutional disturbances reveals the exercise of predominantly anticipatory capabilities, while the main resilience capability leveraged in response to biophysical disturbances is coping capability. The proactive nature of the organizational responses to institutional drivers in the form of regulations is consistent with prevailing literature detailing the presence of sanctions as a driver in selforganization around common pool resource governance (Ostrom, 1990).

The disturbance categories covered in this study are not intended to be an exhaustive list of all possible institutional and/or biophysical disturbances. They represent the most significant ones that we judged to be relevant to the study. As mentioned earlier, other institutional disturbances could take the form of socio-cultural norms or market factors. One of the prevailing socio-cultural norms in the Upper Basin, is the illegal stocking of invasive fish species in certain sections for the purposes of recreational fishing, a continuing legacy of past authorized fish stocking (Johnson et al., 2009). The UCREFRP undertakes invasive fish species containment through educating the public, putting out a blanket kill policy on invasive fish species and also using chemical containment measures in key sections to reduce invasive species presence and facilitate the propagation of endangered fish species. This creates significant ambiguities for our assessments and it was not included. Other disturbances internal to the organization, such as turnover, were similarly not included. The list of disturbances in this study is a first attempt to categorize the impacts of external environmental disturbances on organizations for river restoration. We hope that in future research, the list could be expanded to include more complex and cascading disturbances and their impacts.
The predominant prevalence of coping capabilities as resilience capabilities in response to biophysical disturbances also illustrates the fact that while the principle behind the formation and operation of the programs remains adaptive management, it has not been sufficiently sensitive to changing biophysical conditions. Organizational responses to these still hinge on short-term, stop-gap solutions that mitigate immediate adverse effects to endangered species recovery.

Also significant is the fact that the UCR-EFRP displays adaptive capabilities in response to both institutional and biophysical pulse disturbance events, but not to either of the press disturbance events. This supports the previous contention that the adaptive capabilities are leveraged more in response to short-term disturbances, with very little planned adaptive capacity being built to deal with more complex and long-lasting press disturbances. The LCR-MSCP covers an intensively managed section of the river and apart from anticipatory capabilities leveraged to comply with the ESA, the unique and aggressive water politics of the Lower Basin states (Morrison et al., 1996; Huckleberry and Potts, 2019) as well as the path dependence engendered by extensive dams and diversions and rigid water rights and allocation regimes, there are significant constraints for the program to incorporate adaptive resilience capabilities to changing biophysical press conditions.

A point to highlight here is the fact that the institutional press disturbance in the form of ESA follows a pre-set process for listing that lags far behind the more urgent biophysical press disturbances of megadrought, climate change and continued invasive species management. This time lag can be costly and detrimental to future endangered species recovery efforts. While anticipatory capabilities can help to deal with institutional disturbances, these capabilities need to be leveraged to take into account biophysical disturbances that are already making themselves felt. This is in addition to building adaptive capacity to deal with longer-term press disturbances.

As river restoration in arid regions takes on new and more urgent meaning, and in light of the recent federal shortage declaration on the Colorado River, it is imperative that organizations formed to facilitate the goal of river restoration and healthy, living rivers are constituted in a long-term sustainable manner and are resilient to various disturbances. This study used an in-depth content analysis method to tie the presence of certain intra-organizational diversity attributes to organizational resilience. A key implication the study identified was the need for increased cognitive diversity in decision-making through the incorporation of local and indigenous ecological knowledge that better engages with the conditions of the river systems on the ground. This study contributes to a deeper understanding of organizational resilience, points to vulnerabilities that can be addressed, and highlights the necessity for stronger sensitivity to biophysical conditions and incorporating feedback from them to ensure long-term organizational sustainability for river restoration. 


\section{DATA AVAILABILITY STATEMENT}

The original contributions presented in the study are included in the article/Supplementary Material, further inquiries can be directed to the corresponding author/s.

\section{AUTHOR CONTRIBUTIONS}

This manuscript was conceptualized and written by JS under the supervision and guidance of MS and DW. TL's contribution

\section{REFERENCES}

Aagaard, P. (2012). The challenge of adaptive capability in public organizations: a case study of complexity in crime prevention. Public Manag. Rev. 14, 731-746. doi: 10.1080/14719037.2011.642626

Ajzen, I. (1988). Attitudes, Personality and Behavior. Milton Keynes: Open University Press.

Ajzen, I. (1991). The theory of planned behavior. Org. Behav. Hum. Decision Process. 50, 179-211. doi: 10.1016/0749-5978(91)90020-T

Ajzen, I., and Madden, T. (1986). Prediction of goal-directed behavior: attitudes, intentions, and perceived behavioral control. J. Exp. Soc. Psychol. 22, 453-474. doi: 10.1016/0022-1031(86)90045-4

Ancona, D., and Caldwell, D. (1992). Demography and design: predictors of new product team performance. Org. Sci. 3, 321-341. doi: 10.1287/orsc.3. 3.321

Anderies, J., Janssen, M., and Ostrom, E. (2004). A framework to analyze the robustness of social-ecological systems from an institutional perspective. Ecol. Soc. 9:118. doi: 10.5751/ES-00610-090118

Argyris, C., and Schon, D. (1978). Organizational Learning: A Theory of Action Perspective. Reading, PA: Addison-Wesley.

Arizona Department of Water Resources vs. Mohave County (2015).

Armitage, C., and Conner, M. (2001). Efficacy of the theory of planned behaviour: a meta-analytic review. Br. J. Soc. Psychol. 40, 471-499. doi: 10.1348/014466601164939

Biswas, A. (2004). "IWRM: for sustainable use of water 50 years of international experience with the concept of integrated water management," in Proceedings of the FAO/Netherlands Conference on Water for Food and Ecosystems. Wageningen, 31 .

Bunderson, J., and Sutcliffe, K. (2002). Comparing alternative conceptualizations of functional diversity in management teams: process and performance effects. Acad. Manag. J. 45, 875-893. doi: 10.5465/3069319

Byrne, D. (1971). The Attraction Paradigm. New York, NY: Academic Press.

Cho, T. (2006). The effects of executive turnover on top management team's environmental scanning behavior after an environmental change. J. Bus. Res. 59, 1142-1150. doi: 10.1016/j.jbusres.2006.06.004

Collins, S., Carpenter, S., Swinton, S., Orenstein, D., Childers, D., Gragson, T., et al. (2011). An integrated conceptual framework for long-term social-ecological research. Front. Ecol. Environ. 9, 351-357. doi: 10.1890/ 100068

Conner, M., and Sparks, P. (2020). “Theory of planned behavior and health behavior," in Handbook of Sport Psychology, eds M. Conner and P. Norman (New York, NY: Open University Press; McGraw-Hill Education), 1-18. doi: 10.1002/9781119568124.ch1

CRS (2020). Management of the Colorado River: Water Allocations, Drought, and the Federal Role. Washington, DC: Congressional Research Service.

Duchek, S. (2014). "Growth in the face of crisis: the role of organizational resilience capabilities," in Academy of Management Proceedings (New York, NY: Briarcliff Manor), 13487. doi: 10.5465/ambpp.2014.225

Duchek, S., Raetze, S., and Scheuch, I. (2020). The role of diversity in organizational resilience: a theoretical framework. Bus. Res. 13, 387-423. doi: $10.1007 /$ s40685-019-0084-8

Eagly, A., and Chaiken, S. (1993). The Psychology of Attitudes. New York, NY: Harcourt Brace Jovanovich College Publishers. was in implementing the methods and undertaking intecoder reliability assessment, as well as in providing manuscript feedback. All authors contributed to the article and approved the submitted version.

\section{SUPPLEMENTARY MATERIAL}

The Supplementary Material for this article can be found online at: https://www.frontiersin.org/articles/10.3389/frwa. 2021.733117/full\#supplementary-material

Eagly, A. H., and Chaiken, S. (2007). The advantages of an inclusive definition of attitude. Soc. Cogn. 25, 582-602. doi: 10.1521/soco.2007.25.5.582

Edquist, C., and Johnson, B. (1997). "Institutions and organizations in systems of innovation," in Systems of Innovation: Technologies, Institutions and Organizations, ed C. Edquist (Oxford: Routledge), 41-63.

Fiol, C. (1994). Consensus, diversity, and learning in organizations. Org. Sci. 5, 403-420. doi: 10.1287/orsc.5.3.403

Fishbein, M., and Ajzen, I. (1975). Belief, Attitude, Intention and Behavior: An Introduction to Theory and Research. Reading, PA: Addison-Wesley.

Folke, C., Colding, J., and Berkes, F. (2003). "Synthesis: building resilience and adaptive capacity in social-ecological systems," in Navigating SocialEcological Systems: Building Resilience for Complexity and Change (Cambridge: Cambridge University Press), 352-387. doi: 10.1017/CBO9780511541957.020

Gawronski, B. (2007). Editorial: attitudes can be measured! But what is an attitude? Soc. Cogn. 25, 573-581. doi: 10.1521/soco.2007.25.5.573

Gawronski, B., Hofmann, W., and Wilbur, C. (2006). Are "implicit" attitudes unconscious? Conscious. Cogn. 15, 485-499. doi: 10.1016/j.concog.2005.11.007

Gilbert, J., and Ivancevich, J. (2000). Valuing diversity: a tale of two organizations. Acad. Manag. Perspectiv. 14:93. doi: 10.5465/ame.2000.2909842

Greenwood, R., Hinings, C., and Whetten, D. (2014). Rethinking institutions and organizations. J. Manag. Stud. 51, 1206-1220. doi: 10.1111/joms.12070

GWP (2002). Introducing Effective Water Governance. GWP Technical Paper. Stockholm: Global Water Partnership (GWP).

GWP-TEC (2000). Integrated Water Resources Management. Global Water Partnership, Technical Advisory Committee. Stockholm; Sweden: Global Water Partnership.

Hallgren, K. (2012). Computing inter-rater reliability for observational data: an overview and tutorial. Tutor. Quantitat. Method. Psychol. 8:23. doi: 10.20982/tqmp.08.1.p023

Harrison, D., and Klein, K. (2007). What's the difference? Diversity constructs as separation, variety, or disparity in organizations. Acad. Manag. Rev. 32, 1199-1228. doi: 10.5465/amr.2007.26586096

Haunschild, P., and Sullivan, B. (2002). Learning from complexity: effects of prior accidents and incidents on airlines' learning. Administr. Sci. Quart. 47, 609-643. doi: $10.2307 / 3094911$

Holling, C., and Meffe, G. (1996). Command and control and the pathology of natural resource management. Conserv. Biol. 10, 328-337. doi: 10.1046/j.1523-1739.1996.10020328.x

Huckleberry, J., and Potts, M. (2019). Constraints to implementing the foodenergy-water nexus concept: governance in the Lower Colorado River Basin Author links open overlay panel. Environ. Sci. Pol. 92, 289-298. doi: 10.1016/j.envsci.2018.11.027

Huntjens, P., Lebel, L., Pahl-Wostl, C., Camkin, J., Schulze, R., and Kranz, N. (2012). Institutional design propositions for the governance of adaptation to climate change in the water sector. Glob. Environ. Change 22, 67-81. doi: 10.1016/j.gloenvcha.2011.09.015

Huntjens, P., Pahl-Wostl, C., Rihoux, B., Schlüter, M., Flachner, Z., Neto, S., et al. (2011). Adaptive water management and policy learning in a changing climate: a formal comparative analysis of eight water management regimes in Europe, Africa and Asia. Environ. Pol. Gov. 21, 145-163. doi: 10.1002/eet.571

Jackson, S., Joshi, A., and Erhardt, N. (2003). Recent research on team and organizational diversity: SWOT analyis and implications. J. Manag. 29, 801-830. doi: 10.1016/S0149-2063(03)00080-1 
Jeffrey, P., and Gearey, M. (2004). "Integrated water resources management: lost on the road from ambition to realisation?," WATERMATEX Conference. Beijing.

Johannessen, Å., Gerger Swartling, Å., Wamsler, C., Andersson, K., Arran, J., Hernández Vivas, D., et al. (2019). Transforming urban water governance through social (triple-loop) learning. Environ. Pol. Gov. 29, 144-154. doi: $10.1002 /$ eet. 1843

Johnson, B., Arlinghaus, R., and Martinez, P. (2009). Are we doing all we can to stem the tide of illegal fish stocking? Fisheries 34, 389-394. doi: 10.1577/1548-8446-34.8.389

Kaehler, C., Busatto, F., Becker, G., Hansen, P., and Santos, J. (2014). Relationship between adaptive capability and strategic orientation: an empirical study in a Brazilian Company. iBusiness 6, 1-9. doi: 10.4236/ib.2014.61001

Keeler, R. (2017). Colorado River Basin Salinity Control Forum. Available online at: https://www.coloradoriversalinity.org/

Kilduff, M., Angelmar, R., and Mehra, A. (2000). Top management-team diversity and firm performance: examining the role of cognitions. Org. Sci. 11, 21-34. doi: 10.1287/orsc.11.1.21.12569

Kotschy, K., Biggs, R., Daw, T., Folke, C., and West, P. (2015). "Principle 1 maintain diversity and redundancy," in Principles for Building Resilience, eds R. Biggs, M. Schlüter, and M. Schoon (Cambridge: Cambridge University Press), 50-79. doi: 10.1017/CBO9781316014240.004

Lant, C. (2003). Watershed governance in the United States: the challenges ahead. Water Resour. 126, 21-28. Available online at: opensiuc.lib.siu.edu/ jcwre/vol126/iss1/4/

Laughlin, R. (1991). Environmental disturbances and organizational transitions and transformations: some alternative models. Org. Stud. 12, 209-232. doi: $10.1177 / 017084069101200203$

Mallak, L. (1998). Measuring resilience in health care provider organizations. Health Manpower Manag. 24, 148-152. doi: 10.1108/09552069810215755

McIntosh, M., and Morse, J. (2015). Situating and constructing diversity in semi-structured interviews. Glob. Qualitat. Nurs. Res. 42, 294-320. doi: $10.1177 / 2333393615597674$

Medema, W., and Jeffrey, P. (2005). IWRM and adaptive management: synergy or conflict. NeWater Rep. Ser. 7, 1-43.

Miller, C., Burke, L., and Glick, W. (1998). Cognitive diversity among upperechelon executives: implications for strategic decision processes. Strategic Manag. J. 19, 39-58. doi: 10.1002/(SICI)1097-0266(199801)19:1<39::AIDSMJ932>3.0.CO;2-A

Milliken, F., and Martins, L. (1996). Searching for common threads: understanding the multiple effects of diversity in organizational groups. Acad. Manag. Rev. 21, 402-433. doi: 10.5465/amr.1996.9605060217

Mor Barak, M., Cherin, D., and Berkman, S. (1998). Organizational and personal dimensions in diversity climate: ethnic and gender differences in employee perceptions. J. Appl. Behav. Sci. 34, 82-104. doi: 10.1177/0021886398341006

Morrison, J., Postel, S., and Gleick, P. (1996). The Sustainable Use of Water in the Lower Colorado River Basin. A Joint Report of the Pacific Institute for Studies in Development, Environment and Security and the Global Water Policy Project, Pacific Institute for Studies in Development, Environment and Security. Oakland, CA: Pacific Institute for Studies in Development, Environment and Security.

North, D. (1990). Institutions, Institutional Change and Economic Performance. Cambridge: Cambridge University Press. doi: 10.1017/CBO97805118 08678

Olson, B., Parayitam, S., and Bao, Y. (2007). Strategic decision making: the effects of cognitive diversity, conflict, and trust on decision outcomes. J. Manag. 33, 196-222. doi: 10.1177/01492063062 98657

Ostrom, E. (1990). Governing the Commons: The Evolution of Institutions for Collective Action. Cambridge: Cambridge University Press. doi: $10.1017 /$ СBO9780511807763

Ostrom, E. (2005). In Understanding Institutional Diversity. Princeton, NJ: Princeton University Press.

Ostrom, E. (2009). A general framework for analyzing sustainability of social-ecological systems. Science 325, 419-422. doi: 10.1126/science.117 2133

Ostrom, E. (2011). Background on the institutional analysis and development framework. Pol. Stud. J. 39, 7-27. doi: 10.1111/j.1541-0072.2010. 00394.x
Pahl-Wostl, C. (2009). A conceptual framework for analysing adaptive capacity and multi-level learning processes in resource governance regimes. Glob. Environ. Change 19, 354-365. doi: 10.1016/j.gloenvcha.2009. 06.001

Pahl-Wostl, C., Holtz, G., Kastens, B., and Kneiper, C. (2010). Analyzing complex water governance regimes: the management and transition framework. Environ. Sci. Pol. 13, 571-581. doi: 10.1016/j.envsci.2010.08.006

Pahl-Wostl, C., and Sendzimir, J. (2005). The Relationship between IWRM and Adaptive Management. Osnabrueck: NeWater.

Payne, B., Burkley, M., and Stokes, M. (2008). Why do implicit and explicit attitude tests diverge? the role of structural fit. J. Personal. Soc. Psychol. 94, 16-31. doi: 10.1037/0022-3514.94.1.16

Pickett, S., and White, P. (1985). "Natural disturbance and patch dynamics: an introduction," in The Ecology of Natural Disturbance and Patch Dynamics, eds S. T. A. Pickett and P. S. White (London: Academic Press Inc), 3-13. doi: 10.1016/B978-0-08-050495-7.50006-5

Poteete, A. R., and Ostrom, E. (2004). Heterogeneity, group size and collective action: the role of institutions in forest management. Dev. Change 35, 435-461. doi: 10.1111/j.1467-7660.2004.00360.x

Powell, R. (2010). "Developing institutions to overcome governance barriers to ecoregional conservation," in Landscape-Scale Conservation Planning, eds S. C. Trombulak and R. F. Baldwin (Dordrecht: Springer), 53-66. doi: $10.1007 / 978-90-481-9575-6 \_4$

Ricardo, O. (2000). Racial diversity, business strategy, and firm performance: a resource-based view. Acad. Manag. J. 43, 164-177. doi: 10.2307/1556374

Schoon, M., Robard, M., Meek, C., and Galaz, V. (2015). "Principle 7 - promote polycentric governance systems," in Principles for Building Resilience, eds R. Biggs, M. Schlüter, and M. Schoon (Cambridge: Cambridge University Press), 225-250.

Shavit, A., Kolumbus, A., and Ellison, A. (2016). Two Roads Diverge in a Wood: Indifference to the Difference Between 'Diversity' and 'Heterogeneity' Should be Resisted on Epistemic and Moral Grounds.

Sheppard, B., Hartwick, J., and Warshaw, P. (1988). The theory of reasoned action: a meta-analysis of past research with recommendations for modifications and future research. J. Consum. Res. 15, 325-343. doi: 10.1086/20 9170

Simons, T., Pelled, L., and Smith, K. (1999). Making use of difference: diversity, debate, and decision comprehensiveness in top management teams. Acad. Manag. J. 42, 662-673. doi: 10.5465/256987

Snellen, W., and Schrevel, A. (2004). "IWRM: for sustainable use of water 50 years of international experience with the concept of integrated water management," in Proceedings of the FAO/Netherlands Conference on Water for Food and Ecosystems. Wageningen, 31.

Stirling, A. (2007). A general framework for analysing diversity in science, technology and society. J. Royal Soc. Interface 4, 707-719. doi: 10.1098/rsif.2007.0213

Tsui, A., Egan, T., and O’Reilly, I. I. I., C. (1992). Being different: relational demography and organizational attachment. Administr. Sci. Quart. 37, 549-579. doi: 10.2307/2393472

Tucker, B. (2013). Environmental disturbances, organizational transitions and transformations: a view from the dark side. Crit. Perspectiv. Account. 24, 242-259. doi: 10.1016/j.cpa.2012.01.007

USDOI. (2008). Reclamation: The Law of the River. U.S. Department of the Interior, Bureau of Reclamation. Available online at: https://www.usbr.gov/lc/region/ g1000/lawofrvr.html (accessed July 30, 2020).

Vogus, T., and Sutcliffe, K. (2007). "Organizational resilience: towards a theory and research agenda," in IEEE International Conference on Systems, Man and Cybernetics. Toronto, CA: IEEE, 3418-3422. doi: 10.1109/ICSMC.2007.4414160

Walsh, J., and Ungson, G. (1991). Organizational memory. Acad. Manag. Rev. 16, 57-91. doi: $10.2307 / 258607$

Williams, T., Gruber, D., Sutcliffe, K., Shepherd, D., and Zhao, E. (2017). Organizational response to adversity: fusing crisis management and resilience research streams. Acad. Manag. Ann. 11, 733-769. doi: 10.5465/annals.2015.0134

Young, O. (2010). Institutional dynamics: resilience, vulnerability and adaptation in environmental and resource regimes. Glob. 
Environ. Change 20, 378-385. doi: 10.1016/j.gloenvcha.2009. 10.001

Conflict of Interest: The authors declare that the research was conducted in the absence of any commercial or financial relationships that could be construed as a potential conflict of interest.

Publisher's Note: All claims expressed in this article are solely those of the authors and do not necessarily represent those of their affiliated organizations, or those of the publisher, the editors and the reviewers. Any product that may be evaluated in this article, or claim that may be made by its manufacturer, is not guaranteed or endorsed by the publisher.

Copyright $\odot 2021$ Srinivasan, Lorenzo, Schoon and White. This is an open-access article distributed under the terms of the Creative Commons Attribution License (CC $B Y)$. The use, distribution or reproduction in other forums is permitted, provided the original author(s) and the copyright owner(s) are credited and that the original publication in this journal is cited, in accordance with accepted academic practice. No use, distribution or reproduction is permitted which does not comply with these terms. 